\title{
Relevance of retrovirus quantification in cerebrospinal fluid for neurologic diagnosis

\author{
Carolina Rosadas ${ }^{1,3^{*}}$ and Marzia Puccioni-Sohler ${ }^{1,2,3^{*}}$
}

\begin{abstract}
Different human retroviruses, such as Human Immunodeficiency Virus (HIV) and Human T-cell Lymphotropic Virus (HTLV), can cause neurologic infection. However, a definitive diagnosis may be hampered by several factors. Quantification of the viral or proviral load in cerebrospinal fluid (CSF) may be helpful in the diagnosis of nervous system disorders due to retroviral infection and may influence the treatment approach. The present work discusses retrovirus infection and neurologic impairment, as well as the usefulness of the determination of the HIV and HTLV proviral or viral load in cerebrospinal fluid in cases of neurologic disorder, in light of recent advances in this field. This study also discusses the different molecular techniques for quantifying the proviral load (real-time quantitative PCR, droplet digital PCR, and semi-nested real-time reverse transcription PCR) that are currently available.
\end{abstract}

Keywords: Retrovirus, Cerebrospinal fluid, Viral load, Proviral load, HTLV, HIV

\section{Introduction}

The Retroviridae family comprises enveloped RNA viruses that can infect several hosts. The viral particle presents the enzymes reverse transcriptase and integrase. Thus, after the reverse transcription, the proviral DNA can be integrated into host cell genome [1]. In this context, molecular assays can be used to determine the presence and quantity of both viral RNA and proviral DNA in the infected host cell [2-5]. Human retroviruses, such as Human Immunodeficiency Virus (HIV) and Human T-cell Lymphotropic Virus (HTLV), can cause neurologic infection [6-12]. However, in these cases, a definitive diagnosis can be very challenging and helpful for the early treatment. The difficulty is associated with distinct factors, such as the wide range of symptoms that can be observed in both types of infection and the similarity of those symptoms with those of other diseases. This problem occurs not only in developing countries, where there is a high prevalence of infectious agents, but worldwide. The presence of coinfections and the possibility of secondary nervous system damage due to dual infection are other factors that can complicate the diagnosis [11, 13-16]. The presence of virus in the central nervous system (CNS) of individuals without

\footnotetext{
*Correspondence: carolrosadas@gmail.com; mpuccioni@hucff.ufrj.br ${ }^{1}$ Cerebrospinal Fluid Laboratory, Hospital Universitário Clementino Fraga Filho, Universidade Federal do Rio de Janeiro, Rua Professor Rodolpho Paulo Rocco 255, $3^{\circ}$ andar, Rio de Janeiro 21941-913, Brazil

Full list of author information is available at the end of the article
}

neurologic alterations also hampers a conclusive diagnosis. Therefore, in cases of CNS impairment, such as HTLV1-associated myelopathy and HIV-associated dementia, viral quantification in cerebrospinal fluid (CSF) may clarify the diagnosis $[8,13,17-22]$.

In the current study, we discuss the usefulness of HIV and HTLV-1 quantification in CSF among patients with neurologic disorders due to retrovirus infection, on the basis of the recent knowledge achieved in this field.

\section{Review}

Retrovirus infections and neurologic impairment

HTLV-1 can successfully infect the central nervous system (CNS). Although the great majority of HTLV-1 infected individuals remain asymptomatic throughout their lifetime, about $5 \%$ may present a chronic, incapacitating neurologic disorder [10, 23, 24]. This disorder, called HTLV-1-associated myelopathy/tropical spastic paraparesis (HAM/TSP), is characterized predominantly by spinal cord damage associated with HTLV-1 infection [10, 25].

Regarding HIV infection, severe neurocognitive conditions, usually resulting in death, have been detected in HIV-infected individuals since the beginning of the HIV epidemic $[6,26]$. This alteration was observed in persons with advanced HIV-1 infection and was called HIVAssociated Dementia (HAD) [27]. A few years later, milder forms of neurocognitive impairment in HIV-1- 
infected persons were reported, occurring even before the onset of advanced systemic disease [28]. After the introduction of combination antiretroviral therapy (cART), the incidence of HAD decreased dramatically [29]. However, milder forms of HIV-associated neurologic disorders became highly prevalent. Thus, a new denomination was suggested: HIV-associated neurocognitive disorders (HAND) $[7,27]$. According to this new terminology, HAND can be further classified into asymptomatic neurocognitive impairment (ANI), mild neurocognitive disorder (MND), and HIV-associated dementia (HAD). HAND is estimated to affect up to $50 \%$ of HIV-infected individuals [7, 27]. It is important to note that the prevalence of HAD decreased in the cART era, but for mild to moderate HAND forms. In fact, the prevalence of HAND in HIV-infected patients without AIDS increased from 29 to $36 \%$ after the implementation of combined antiretroviral therapy. There was no significant difference in the prevalence of HAND among AIDS patients [9].

\section{HTLV proviral load in CSF}

According to WHO guidelines for HAM/TSP diagnosis, a patient can be classified under definitive HAM/TSP in the presence of chronic progressive spastic paraparesis associated with antibodies detection in both blood and CSF. Some individuals, however, do not present antibodies in CSF or do not present the classical symptoms of disease, despite the presence of antibodies in both compartments. Such individuals are classified under probable HAM/TSP [30]. Moreover, in cases of recent infection and of passive transfer of antibodies (as can occur in vertical transmission), antibodies detection is not recommended due to false-positive or falsenegative results [31]. It is important to highlight that antibodies can be passively transferred through the blood-CSF barrier even in asymptomatic individuals [17].

The detection of HTLV-1 antibodies is done by screening (ELISA) and confirmatory tests (Western blot). Some patients can present indeterminate or discordant Western blot results [32, 33]. The same can occur in HIV diagnosis [34]. In this context, tests that are able to detect and quantify viral genome can be very useful. The HTLV-1 proviral load (PVL) in blood is higher in HAM/TSP patients than in asymptomatic carriers. However, previous studies have failed to determine a reliable cutoff value for an accurate HAM/TSP diagnosis [35, 36].

Regarding the PVL in CSF, patients with HAM/TSP were found to present a higher PVL compared with asymptomatic HTLV-1-infected individuals [13, 17, 20, 21, 37]. Moreover, in HAM/TSP patients, the PVL CSF/PVL blood ratio was always higher than 1 in HAM/TSP and lower than 1 in AC [38] PVL in CSF inverse correlated with intrathecal synthesis of HTLV-1 antibodies (HTLV-1 AI) [12]. Another interesting point is that PVL in CSF combined to intrathecal synthesis of HTLV-1 antibodies analysis showed to be useful in discriminating between HAM/TSP and multiple sclerosis (MS) [13]. This is extremely important because HTLV and MS present very similar symptoms.

Therefore, the quantification of the PVL in CSF may be a good marker for HAM/TSP diagnosis, mainly when associated with other tests, such as HTLV-1 AI.

\section{HIV viral and proviral load in CSF}

The determination of the HIV viral load in blood is widely used to assess the disease progression and the response to antiretroviral therapy. As previously mentioned, HIV can infect the CNS, and HAND can be observed even in patients with adequate control of viral replication in plasma $[7-9,18,22,39]$. The mechanism that leads to the persistence of neurologic impairment in patients with suppressed viral replication in the bloodstream is poorly understood. Some authors consider chronic inflammation, the presence of coinfections (such as $\mathrm{HCV}$ ), drug abuse, aging, and antiretroviral drug effects as factors that can contribute to the persistence of HAND [15]. In this context, HIV compartmentalization might play an important role in nervous system damage. To understand HIV compartmentalization and its association with HAND development, as well as acquired drug resistance, some basic concepts of viral biology are discussed.

HIV presents a high mutation rate, which can result in the coexistence of viral quasispecies within a host. These quasispecies evolve as a result of selection pressures, such as those imposed by antiviral therapy, and can be restricted to cells or tissues (compartmentalization) [40]. Previous studies have described the HIV compartmentalization in the CNS, which leads to selective replication of distinct HIV quasispecies, resulting in resistance confined to the CNS $[19,41]$. It has also been pointed out that the mutated virus may cause further viremia and may be related to resistance to cART; Fig. 1 presents this mechanism. A recent study showed that HIV-infected individuals presented more resistant virus in CSF than in blood. This occurred in both antiretroviral-naïve and treated patients, being more frequent in the latter [42]. The administration of drugs that are poorly distributed in the CNS is a factor that can contribute to the development of drug-resistant virus in the nervous system. Suboptimal adherence to the treatment regimen may also lead to insufficient drug concentration in CSF, which may also contribute to viral resistance $[3,8]$.

Thus, several studies have shown that HIV can escape in CSF despite viral suppression in blood [3, 8, 18, 22, 43]. This evasion can contribute to discordant viral loads and to a high viral load in CSF. A study of the HIV proviral load in blood and CSF among HIV-seropositive individuals with and without HAND found that the CSF proviral load was greater in individuals with HAND than in those 


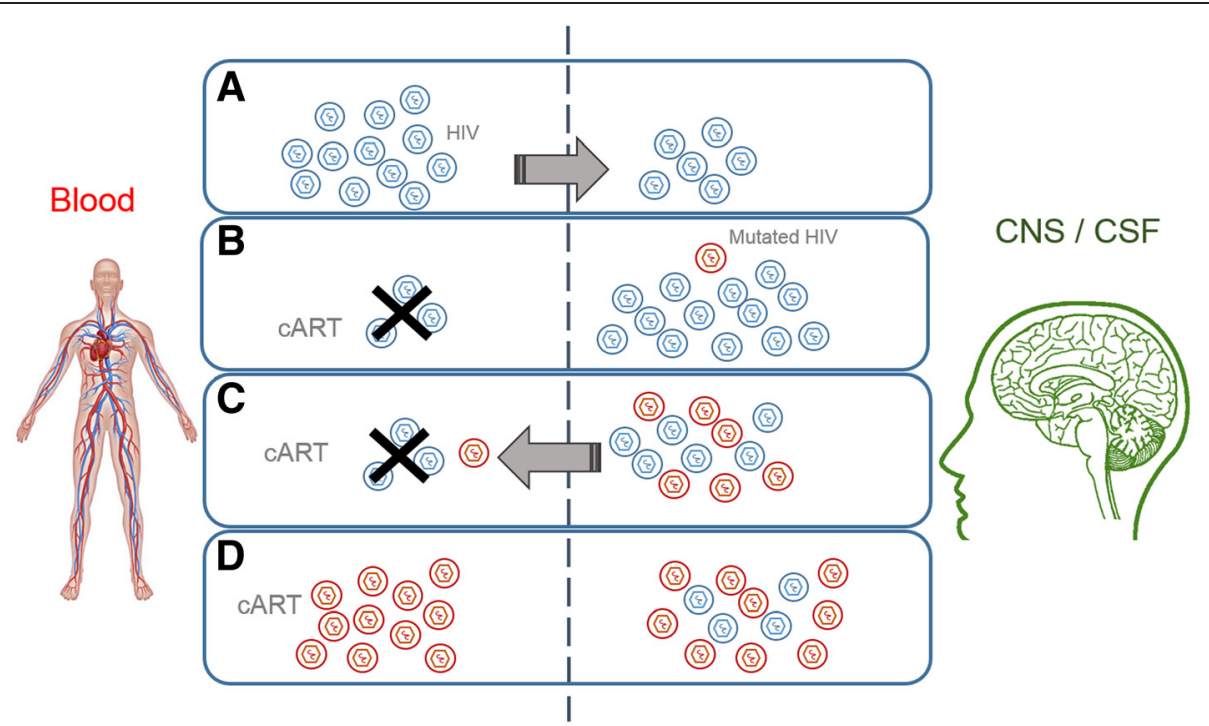

Fig. 1 Mechanism of HIV-acquired drug resistance with the central nervous system as reservoir. a Initial phase of HIV infection: HIV is replicating in blood and access the CNS. $\mathbf{b}$ CART is initiated and controls the viremia. However, depending on the drug regimen, the drug access to the CNS is poor, and HIV can efficiently replicate in this reservoir. As replication occurs, a mutated virus can be formed (compartmentalization). c Mutated HIV enters the bloodstream. The mutated virus is able to replicate more efficiently in the cART poor environment (CNS) and could get into the bloodstream. $\mathbf{d}$ The mutant drug-resistant virus replicates efficiently even with CART therapy. In such cases, the medication has to be changed. The higher replication rate in the CNS is associated with the high proviral load in the CNS despite the proviral load in blood and is associated with neurologic abnormalities in HIV-infected patients

without HAND. Moreover, the PVL in seropositive patients was greater in CSF than in blood. The proviral load was also observed to be greater in the blood and CSF of subjects with more advanced systemic disease and HAND [5]. Other studies have corroborated these findings, showing a high viral load in CSF among patients with HAD [44].

These data highlight the importance of the quantification of the proviral or viral load in CSF among HIV-infected patients presenting neurologic disturbance and/or drug resistance. In such cases, genotyping tests of CSF virus are extremely important. In fact, some studies have reported successful genotyping in CSF in cases in which it was not possible to apply genotyping in blood [45].

\section{Antiretroviral treatment and the proviral load}

Previous studies have reported the effect of antiretroviral treatment on the HIV proviral load. In particular, the proviral load in CSF was shown to decrease after the implementation of a therapeutic regimen with drugs with improved CNS penetration [43].

Indeed, the drug concentration in the CNS seems to be crucial for viral control in the nervous system. A recent study tested two different therapeutic regimens with distinct concentrations of darunavir. Only two patients presented detectable viral genome in CSF, and those two had the lower concentration of the drug in CSF despite the prescribed dosage of orally administered drug, confirming that CSF assessment is an important issue [46].
Some drugs used as monotherapy, such as lopinavir/ ritonavir and zidovudine, had a significant effect on decreasing CSF replication. In contrast, didanosine and saquinavir were not able to control viral replication in CSF. Abacavir was also tested as an adjunctive therapy in patients presenting HAD, with no effect in CSF HIV RNA. In this context, a CNS penetrationeffectiveness (CPE) score was proposed. According to the CPE, the antiretrovirals are scored from 1 to 4 (with 4 indicating the most neuro-effective drug). This is determined based on the drug characteristics, pharmacokinetic features, and pharmacodynamic properties. The composite CPE can be calculated by summing single drug scores to obtain the treatment score. Usually, a higher CPE score is associated with a lower viral load in CSF $[47,48]$.

Another important point associated with the successful control of viral replication in CSF is related to viral resistance. Thus, the therapeutic regimen should be modified according to the results obtained by genotypic resistance testing in CSF samples.

Regarding HTLV infection, the specific therapy for HAM/TSP remains very disappointing, and symptomatic treatment is still the most commonly used therapy [10]. There are few studies showing the impact of therapy on the CSF PVL of HAM/TSP individuals. In one report, after the corticosteroid therapy, the PVL in blood decreased, but the PVL in CSF remained unchanged. The patient presented an acute onset, a rapid progression, and 
repeated exacerbation of neurologic symptoms, which is not the classical presentation of HAM/TSP [20].

\section{Molecular assays to determine the proviral and viral load} Currently, quantitative real-time polymerase chain reaction (qPCR) and reverse transcription (RT)-qPCR are the standard and most commonly used techniques to determine the proviral or viral load $[37,49,50]$. qPCR is known to have high sensitivity, which is associated with the ability to amplify the target gene, and high specificity, which is related to primer annealing. In this context, there are two main systems for the identification of the sign: the use of fluorometric probes (such as the TaqMan system) and the use of intercalating dyes (such as SYBR Green). The use of a fluorometric probe increases the assay specificity once the probe hybridizes to a complementary target sequence in the target DNA, but not to nonspecific PCR products or primer dimers, which may happen when intercalating dyes are used [51, 52]. However, qPCR presents limitations that can influence the accuracy of the test. The dependence on a standard curve, for example, may result in high inter-assay variability, mainly in compartments with a low number of cells, such as CSF [53].

In this context, a novel technique, droplet digital PCR (ddPCR), can also be used for viral or proviral load quantification. The advantage of this technique is that it does not require a standard curve. In fact, ddPCR allows the direct absolute quantification of a target gene, which can positively influence the accuracy of the PVL quantification. In a recent study, ddPCR presented low intra- and inter-assay variability in the determination of the HTLV-1 PVL in CSF of infected patients. The same study concluded that, regarding the HTLV-1 proviral load in peripheral blood mononuclear cells (PBMCs), the inter-assay variability of ddPCR was lower compared with qPCR [37]. It is important to note, however, that ddPCR presented false-positive signals when it was used to detect the viral load in HIV-infected individuals [54].

Regarding HIV infection, because some individuals can present viral replication suppressed below the detection limit of the available diagnostic methods [39], some authors have suggested the use of a semi-nested realtime reverse transcription PCR assay to determine the plasma viral load. In this technique, two successive PCR reactions are done to increase the sensitivity of the test and, consequently, reduce the limit of detection [55]. Thus, semi-nested RT-qPCR may be an interesting alternative in patients with a low viral load. Nevertheless, no study has applied this technique in CSF.

Regardless of the chosen technique, prior validation is essential, that is, before implementation in CSF routine analysis. Cross-validation by multiple laboratories is indicated.

\section{Conclusions}

The determination of the viral or proviral load in CSF of HTLV-1- and HIV-infected individuals with neurologic disease may be a good marker for diagnosis, considering the proximity of the lesion and the local infection. The association of PVL measurement with other tests, such as PVL in blood and intrathecal synthesis of specific antibodies analysis in HTLV infection and HIV genotyping, might bring an important contribution to clinicians. In some cases, it can make the difference for a conclusive diagnosis or even to therapeutic approach. However, prior validation of molecular assays before implementation in laboratorial routine is essential, mainly regarding the CSF examination. Many laboratories use the same methodology applied in blood, forgetting that CSF is a body fluid with different constituents that may interfere in laboratory tests. Even greater emphasis should be given to HTLV, which, being a neglected disease, does not have approved commercial kits for use in CSF testing; thus, "in-house" tests are mandatorily used. In this case, the international standardization of tests would be beneficial for the acquisition of reliable and comparable results that would make possible a better clinical interpretation of the laboratory findings of patients.

\section{Competing interests}

The authors declare that they have no competing interests.

\section{Authors' contributions}

CR - Literature review, study design, data collection, data analysis, data interpretation, writing, figure design. MPS- Data analysis, data interpretation, writing, review. Both authors read and approved the final manuscript.

\section{Acknowledgement}

This work was supported by Fundação de Amparo a Pesquisa do Estado do Rio de Janeiro (FAPERJ) and a PhD fellowship to C.R. from Coordenação de Aperfeiçoamento de Pessoal de Nível Superior (CAPES), Brazil.

This work was supported by Fundação de Amparo a Pesquisa do Estado do Rio de Janeiro (FAPERJ) and a PhD fellowship to C.R. from Coordenação de Aperfeiçoamento de Pessoal de Nível Superior (CAPES), Brazil.

\section{Author details}

${ }^{1}$ Cerebrospinal Fluid Laboratory, Hospital Universitário Clementino Fraga Filho, Universidade Federal do Rio de Janeiro, Rua Professor Rodolpho Paulo Rocco 255, $3^{\circ}$ andar, Rio de Janeiro 21941-913, Brazil. ${ }^{2}$ Neuroinfection Unit, Hospital Universitário Gaffrée e Guinle, Universidade Federal do Estado do Rio de Janeiro, Rua Mariz e Barros, 775, Rio de Janeiro 20270-004, Brazil. ${ }^{3}$ Laboratório de Líquido Cefalorraquiano, Serviço de Patologia Clínica, Hospital Universitário Clementino Fraga Filho, Universidade Federal do Rio de Janeiro, Rua Professor Rodolpho Paulo Rocco 255, $3 \pm$ andar, Rio de Janeiro, RJ 21941-913, Brazil.

Received: 5 February 2015 Accepted: 21 July 2015

Published online: 08 August 2015

\section{References}

1. Verdonck K, González E, Van Dooren S, Vandamme A-M, Vanham G, Gotuzzo E. Human T-lymphotropic virus 1: recent knowledge about an ancient infection. Lancet Infect Dis. 2007;7:266-81.

2. Nagai M, Usuku K, Matsumoto W, Kodama D, Takenouchi N, Moritoyo T, et al. Analysis of HTLV-I proviral load in 202 HAM/TSP patients and 243 asymptomatic HTLV-I carriers: high proviral load strongly predisposes to HAM/TSP. J Neurovirol. 1998;4:586-93. 
3. Canestri A, Lescure F-X, Jaureguiberry S, Moulignier A, Amiel C, Marcelin AG, et al. Discordance between cerebral spinal fluid and plasma HIV replication in patients with neurological symptoms who are receiving suppressive antiretroviral therapy. Clin Infect Dis. 2010;50:773-8.

4. Rosadas C, Cabral-Castro MJ, Vicente ACP, Peralta JM, Puccioni-Sohler M. Validation of a quantitative real-time PCR assay for HTLV-1 proviral load in peripheral blood mononuclear cells. J Virol Methods. 2013;193:536-41.

5. Schmid P, Conrad A, Syndulko K, Singer EJ, Handley D, Li X, et al. Quantifying HIV-1 proviral DNA using the polymerase chain reaction on cerebrospinal fluid and blood of seropositive individuals with and without neurologic abnormalities. J Acquir Immune Defic Syndr. 1994;7:777-88.

6. Zayyad Z, Spudich S. Neuropathogenesis of HIV: From Initial Neuroinvasion to HIV-Associated Neurocognitive Disorder (HAND). Curr HIV/AIDS Rep. 2015;12(1):16-24.

7. Lamers SL, Fogel GB, Nolan DJ, McGrath MS, Salemi M. HIV-associated neuropathogenesis: a systems biology perspective for modeling and therapy. Biosystems. 2014;119:53-61.

8. Peluso MJ, Ferretti F, Peterson J, Lee E, Fuchs D, Boschini A, et al. Cerebrospinal fluid HIV escape associated with progressive neurologic dysfunction in patients on antiretroviral therapy with well controlled plasma viral load. AIDS. 2012;26:1765-74.

9. Heaton RK, Franklin DR, Ellis RJ, McCutchan JA, Letendre SL, Leblanc S, et al. $\mathrm{HIV}$-associated neurocognitive disorders before and during the era of combination antiretroviral therapy: differences in rates, nature, and predictors. J Neurovirol. 2011;17:3-16.

10. Gessain A, Mahieux R. Tropical spastic paraparesis and HTLV-1 associated myelopathy: clinical, epidemiological, virological and therapeutic aspects. Rev Neurol (Paris). 2012;168:257-69.

11. Biswas HH, Engstrom JW, Kaidarova Z, Garratty G, Gibble JW, Newman BH, et al. Neurologic abnormalities in HTLV-I- and HTLV-II-infected individuals without overt myelopathy. Neurology. 2009;73:781-9.

12. Puccioni-Sohler M, Rios M, Bianco C, Zhu SW, Oliveira C, Novis SA, et al. An inverse correlation of HTLV-I viral load in CSF and intrathecal synthesis of HTLV-I antibodies in TSP/HAM. Neurology. 1999;53:1335-9.

13. Puccioni-Sohler M, Yamano $Y$, Rios M, Carvalho SMF, Vasconcelos CCF, Papais-Alvarenga $R$, et al. Differentiation of HAM/TSP from patients with multiple sclerosis infected with HTLV-I. Neurology. 2007;68:206-13.

14. Mendes GB, Kalil RS, Rosadas C, de Freitas MRG, Puccioni-Sohler M Temporal lesions and widespread involvement of white matter associated with multi-organ inflammatory disease in human T-lymphotropic virus type 1-associated myelopathy/tropical spastic paraparesis (HAM/TSP). Int J Infect Dis. 2014;25:1-3.

15. Gill AJ, Kolson DL. Chronic inflammation and the role for cofactors (hepatitis C, drug abuse, antiretroviral drug toxicity, aging) in HAND persistence. Curr HIV/AIDS Rep. 2014;11:325-35.

16. Rosadas C, Mendes GB, Puccioni-Sohler M. Inflammation Inducing Central Nervous System Damage in HTLV-1 Infection. Inflammation Cell Signaling 2014;1(5):10-14800/ics.233.

17. Puccioni-Sohler M, Rios M, Carvalho SM, Gonçalves RR, Oliveira C, Correa RB, et al. Diagnosis of HAM/TSP based on CSF proviral HTLV-I DNA and HTLV-I antibody index. Neurology. 2001;57:725-7.

18. Edén A, Fuchs D, Hagberg L, Nilsson S, Spudich S, Svennerholm B, et al. HIV-1 viral escape in cerebrospinal fluid of subjects on suppressive antiretroviral treatment. J Infect Dis. 2010;202:1819-25.

19. Khoury MN, Tan CS, Peaslee M, Koralnik IJ. CSF viral escape in a patient with HIV-associated neurocognitive disorder. J Neurovirol. 2013;19:402-5.

20. Hayashi D, Kubota R, Takenouchi N, Nakamura T, Umehara F, Arimura K, et al. Accumulation of human T-lymphotropic virus type I (HTLV-I)-infected cells in the cerebrospinal fluid during the exacerbation of HTLV-I-associated myelopathy. J Neurovirol. 2008;14:459-63.

21. Lezin A, Olindo S, Oliere S, Varrin-Doyer M, Marlin R, Cabre P, et al. Human T lymphotropic virus type I (HTLV-I) proviral load in cerebrospinal fluid: a new criterion for the diagnosis of HTLV-l-associated myelopathy/ tropical spastic paraparesis? J Infect Dis. 2005;191:1830-4.

22. Calcagno A, Atzori C, Romito A, Ecclesia S, Imperiale D, Audagnotto S, et al. Cerebrospinal fluid biomarkers in patients with plasma HIV RNA below 20 copies/mL. J Int AIDS Soc. 2014;17(4 Suppl 3):19719.

23. Cook LB, Elemans M, Rowan AG, Asquith B. HTLV-1: persistence and pathogenesis. Virology. 2013;435:131-40.

24. Morgan O. HTLV-1 Associated Myelopathy/Tropical Spastic Paraparesis How Far have We Come? West Indian Med J. 2011;60(5):505-12.
25. Osame M, Usuku K, Izumo S, ljichi N, Amitani H, lgata A, et al. HTLV-I associated myelopathy, a new clinical entity. Lancet. 1986;1:1031-2.

26. Snider WD, Simpson DM, Nielsen S, Gold JW, Metroka CE, Posner JB. Neurological complications of acquired immune deficiency syndrome: analysis of 50 patients. Ann Neurol. 1983;14:403-18.

27. Antinori A, Arendt G, Becker JT, Brew BJ, Byrd DA, Cherner M, et al. Updated research nosology for HIV-associated neurocognitive disorders. Neurology. 2007;69:1789-99.

28. Grant I, Atkinson JH, Hesselink JR, Kennedy CJ, Richman DD, Spector SA, et al. Evidence for early central nervous system involvement in the acquired immunodeficiency syndrome (AIDS) and other human immunodeficiency virus (HIV) infections. Studies with neuropsychologic testing and magnetic resonance imaging. Ann Intern Med. 1987;107:828-36.

29. Bhaskaran K, Mussini C, Antinori A, Walker AS, Dorrucci M, Sabin C, et al. Changes in the incidence and predictors of human immunodeficiency virus-associated dementia in the era of highly active antiretroviral therapy. Ann Neurol. 2008:63:213-21.

30. Osame M. Review of WHO Kagoshima meeting and diagnostic guidelines for HAM/TSP. In: Human retrovirology: HTLV. Volume Osame M. 1990. p. 191-7.

31. Tamegão-lopes BP, Rezende PR, Cunha LM. Carga proviral do HTLV-1 e HTLV-2: um método simples através da PCR quantitativa em tempo real HTLV-1 and HTLV-2 proviral load: a simple method using quantitative real-time PCR. Rev Soc Bras Med Trop. 2006;39(6):548-52.

32. Waziri A, Soldan SS, Graf MD, Nagle J, Jacobson S. Characterization and sequencing of prototypic human T-lymphotropic virus type 1 (HTLV-1) from an HTLV-1/2 seroindeterminate patient. J Virol. 2000;74:2178-85.

33. Abrams A, Akahata Y, Jacobson S. The prevalence and significance of HTLV-I/II seroindeterminate Western blot patterns. Viruses. 2011;3:1320-31.

34. Tebourski F, Slim A, Elgaaied A. The significance of combining World Health Organization and Center for Disease Control criteria to resolve indeterminate human immunodeficiency virus type-1 Western blot results. Diagn Microbiol Infect Dis. 2004;48:59-61.

35. Brito S, Furtado S, Andrade RG, Romanelli F, Ribeiro MA, Ribas G, Freitas D, Proietti C, Martins ML, Ba A, Tsp HAM: Monitoring the HTLV-1 Proviral Load in the Peripheral Blood of Asymptomatic Carriers and Patients With HTLV-Associated Myelopathy/Tropical Spastic Paraparesis From a Brazilian Cohort: ROC Curve Analysis to Establish the Threshold for Risk Disease. J Med Virol. 2012;84(4):664-71.

36. Fernanda M, Grassi R, Olavarria VN, Kruschewsky RDA, Correia LCL, Maurı C et al. Human T Cell Lymphotropic Virus Type 1 (HTLV-1) Proviral Load of HTLV-Associated Myelopathy/Tropical Spastic Paraparesis (HAM/TSP) Patients According to New Diagnostic Criteria of HAM/TSP. J Med Virol. 2011;83(7):1269-74.

37. Brunetto GS, Massoud R, Leibovitch EC, Caruso B, Johnson K, Ohayon J, et al. Digital droplet PCR (ddPCR) for the precise quantification of human T-lymphotropic virus 1 proviral loads in peripheral blood and cerebrospinal fluid of HAM/TSP patients and identification of viral mutations. J Neurovirol. 2014;20:341-51.

38. Nagai M, Yamano Y, Brennan MB, Mora CA, Jacobson S. Increased HTLV-I proviral load and preferential expansion of HTLV-I Tax-specific CD8+ T cells in cerebrospinal fluid from patients with HAM/TSP. Ann Neurol. 2001;50:807-12.

39. Doyle T, Geretti AM. Low-level viraemia on HAART: significance and management. Curr Opin Infect Dis. 2012;25:17-25.

40. Falcone EL, Adegbulugbe AA, Sheikh V, Imamichi H, Dewar RL, Hammoud DA, et al. Cerebrospinal fluid HIV-1 compartmentalization in a patient with AIDS and acute varicella-zoster virus meningomyeloradiculitis. Clin Infect Dis. 2013:57:e135-42.

41. Smit TK, Brew BJ, Tourtellotte W, Morgello S, Gelman BB, Saksena NK Independent evolution of human immunodeficiency virus (HIV) drug resistance mutations in diverse areas of the brain in HIV-infected patients, with and without dementia, on antiretroviral treatment. J Virol. 2004;78:10133-48.

42. Soulie C, Descamps D, Grudé M, Schneider V, Trabaud M-A, Morand-Joubert L, et al. Antiretroviral-naive and -treated HIV-1 patients can harbour more resistant viruses in CSF than in plasma. J Antimicrob Chemother. 2015;70:566-72.

43. Béguelin $C$, Vázquez $M$, Bertschi M, Yerly $S$, de Jong $D$, Rauch $A$, et al. Viral escape in the CNS with multidrug-resistant HIV-1. J Int AIDS Soc. 2014;17(4 Suppl 3):19745.

44. Ritola K, Robertson K, Fiscus SA, Hall C, Swanstrom R. Increased human immunodeficiency virus type 1 (HIV-1) env compartmentalization in the presence of HIV-1-associated dementia. J Virol. 2005;79:10830-4. 
45. Rotta I, Raboni SM, Ribeiro CEL, Riedel M, da Winhescki MG, Smith DM, et al. Cerebrospinal fluid can be used for HIV genotyping when it fails in blood. Arq Neuropsiquiatr. 2014;72:506-9.

46. Di Yacovo MS, Moltó J, Ferrer E, Curran A, Else L, Gisslén M et al. Antiviral activity and CSF concentrations of $600 / 100 \mathrm{mg}$ of darunavir/ritonavir once daily in HIV-1 patients with plasma viral suppression. J Antimicrob Chemother. 2015;70(5):1513-6.

47. Calcagno A, Di Perri G, Bonora S. Pharmacokinetics and pharmacodynamics of antiretrovirals in the central nervous system. Clin Pharmacokinet. 2014;53:891-906

48. Letendre S, Marquie-Beck J, Capparelli E, Best B, Clifford D, Collier AC, et al. Validation of the CNS Penetration-Effectiveness rank for quantifying antiretroviral penetration into the central nervous system. Arch Neurol. 2008;65:65-70

49. Hayden RT, Gu Z, Ingersoll J, Abdul-Ali D, Shi L, Pounds S, et al. Comparison of droplet digital PCR to real-time PCR for quantitative detection of cytomegalovirus. J Clin Microbiol. 2013;51:540-6.

50. Strain MC, Lada SM, Luong T, Rought SE, Gianella S, Terry VH, et al. Highly precise measurement of HIV DNA by droplet digital PCR. PLOS ONE. 2013;8, e55943.

51. Heid CA, Stevens J, Livak KJ, Williams PM. Real time quantitative PCR. Genome Res. 1996:6:986-94.

52. Holland PM, Abramson RD, Watson R, Gelfand DH. Detection of specific polymerase chain reaction product by utilizing the $5^{\prime}-3^{\prime}$ exonuclease activity of Thermus aquaticus DNA polymerase. Proc Natl Acad Sci U S A. 1991;88:7276-80

53. Lee T-H, Chafets DM, Busch MP, Murphy EL. Quantitation of HTLV-I and II proviral load using real-time quantitative PCR with SYBR Green chemistry. J Clin Virol. 2004;31:275-82.

54. Kiselinova M, Pasternak AO, De Spiegelaere W, Vogelaers D, Berkhout B, Vandekerckhove L. Comparison of droplet digital PCR and seminested real-time PCR for quantification of cell-associated HIV-1 RNA. PLOS ONE. 2014;9, e85999.

55. Pasternak AO, Adema KW, Bakker M, Jurriaans S, Berkhout B, Cornelissen M et al. Highly sensitive methods based on seminested real-time reverse transcription-PCR for quantitation of human immunodeficiency virus type 1 unspliced and multiply spliced RNA and proviral DNA. J Clin Microbiol. 2008;46:2206-11

\section{Submit your next manuscript to BioMed Central and take full advantage of:}

- Convenient online submission

- Thorough peer review

- No space constraints or color figure charges

- Immediate publication on acceptance

- Inclusion in PubMed, CAS, Scopus and Google Scholar

- Research which is freely available for redistribution 